\title{
Opioid prescription patterns among urologists as compiled from within Medicare
}

Michael Callegari, MD, MBA ${ }^{1}$; Tarun Jella, MPH²; Amr Mahran, MD, MS ${ }^{1}$; Anood Alfahmy ${ }^{2}$; Wade Muncey, $\mathrm{MD}^{1}$; Anish Patel, MD, MBA ${ }^{1}$; Aram Loeb, MD ${ }^{1}$; Nannan Thirumavalavan, $\mathrm{MD}^{1}$

${ }^{1}$ Urology Institute, University Hospitals Cleveland Medical Center, Cleveland, OH, United States; ${ }^{2}$ Case Western Reserve University School of Medicine, Cleveland, OH, United States

Cite as: Callegari M, Jells T, Mahran A, et al. Opioid prescription patterns among urologists as compiled from within Medicare. Can Urol Assoc J 2021 May 11; Epub ahead of print. http://dx.doi.org/10.5489/cuaj.7086

Published online May 11, 2021

Correspondence: Dr. Michael Callegari, Urology Institute, University Hospitals Cleveland Medical Center, Cleveland, OH, United States; Michael.Callegari@uhhospitals.org

$* * *$

\section{Abstract}

Introduction: We aimed to evaluate opioid prescribing patterns of urologists across the United States (U.S.) and the District of Columbia (D.C.) using publicly available data from Medicare Part D. Our secondary analysis was to identify any loco-regional trends that may exist within the U.S.

Methods: We queried publicly reported information from the Part D Prescriber database, which is compiled from beneficiaries enrolled within the Medicare Part D prescription drug program. Only providers with the specialty description of urologist were included within this study. Results: Between 2013 and 2017, a five-year average of 452901 opioid claims by 9640 urologists - amounting to \$5 357114 (USD) and comprising 3.78\% of all claims made - were identified. The state of Maine featured the highest percentage of opioid claims in relation to all claims (5.81\%). West Virginia had the greatest average total opioid claims per provider (90), while Michigan featured the highest average proportion of opioid claims per provider (10.63\%). The fewest opioid claims were processed within the Mid-Atlantic and New England regions. Conclusions: A multitude of factors likely contributes to variability between states. Urologists should be increasingly aware of their individual prescription tendencies and use available drug 
monitoring programs in order to reduce unnecessary prescriptions, all while providing more targeted and appropriate pain management.

\section{Introduction}

In 2017, the United States Department of Health and Human Services (HHS) declared the US to be within the midst of an nation-wide opioid crisis. ${ }^{1}$ During the same year, according to the Centers for Disease Control and Prevention (CDC), as many as 20\% of all patients were given either acute ( $</=3$ months duration) or chronic ( $>3$ months in duration) pain-related diagnoses (excluding cancer related pain). ${ }^{2}$ Despite advocacy for reduced opioid prescribing by a variety of stakeholders, unnecessary prescribing remains rampant..$^{3-5}$

Within the field of Urology, the overuse of opioid prescribing is well documented. Recent estimates suggest as much as $60 \%$ of post procedural opioids going unused, furthering the potential for misuse and abuse ${ }^{6-8}$ In conjunction with $\mathrm{CDC}$ recommendations, the American Urologic Association (AUA) has published a unifying position statement, recommending limits of 50 Morphine milligram equivalents (MME) for fewer than 7 days. Furthermore the association has recommended Urologists disperse the fewest number of opioid prescriptions and utilize the least potent modalities possible while addressing postoperative pain. ${ }^{3,9}$ Given that a majority of outpatient Urology encounters involve some degree of pain and subsequent pain management, understanding contemporary opioid prescribing patterns is essential in order to optimize clinical protocols, evaluate policy efforts, and mitigate risk for both patients and their healthcare providers. ${ }^{10-13}$ Although the persistence of unnecessary opioid prescribing has been well documented within urology literature, there remains a dearth of information describing regional variations in prescribing practices. Variations in opioid-related practice patterns across hospitals, states, and regions may provide insight into best practices for responsible pain management protocols and help appraise the efforts of local and state policy interventions to help curb the opioid epidemic.

The goals of the present study were to evaluate regional trends and practice variations in opioid prescribing patterns amongst Urologists having submitted claims to the Center for Medicare and Medicaid services Part D program. We hypothesized that opioid prescriptions by urologists were higher in years prior to 2017, compared to the year 2017 when the national opioid crisis was declared. 


\section{Methods}

\section{Dataset}

Data was compiled and extracted from publicly available Medicare Part D prescription drug program public use files (PUF) for the years 2013 - 2017. The Medicare dataset was selected, in part, for its wide variety of variables related to state, local, and individual provider level prescription patterns, in concordance with previously published methodologies in other surgical subfields. ${ }^{14-19}$ These data sets include approximately 70\% of all Medicare Part D beneficiaries. Medical providers identified with the specialty descriptor of Urologist were incorporated into our analysis. We excluded data from unincorporated territories Puerto Rico, Marshall Islands, American Samoa, Guam and U.S. Virgin Islands.

\section{Variables}

Variables included were year, state, National Provider Identifier (NPI), total claim count, total drug cost, total day supply, beneficiary count, opioid claim count, opioid drug cost, opioid day supply and beneficiary count.

\section{State-level and regional analysis}

States were organized into regions within the CMS database (Figure I). These regions were East North Central: Illinois (IL), Indiana (IN), Michigan (MI), Ohio (OH), Wisconsin (WI); East South Central: Alabama (AL), Kentucky (KY), Mississippi (MS), Tennessee (TN); Mid Atlantic: New Jersey (NJ), New York (NY), Pennsylvania (PA); Mountain: Arizona (AZ), Colorado (CO), Idaho (ID), Montana (MT), New Mexico (NM), Nevada (NV), Utah (UT), Wyoming (WY); New England: Connecticut (CT), Massachusetts (MA), Maine (ME), New Hampshire (NH), Rhode Island (RI), Vermont (VT); Pacific: Alaska (AK), California (CA), Hawaii (HI), Oregon (OR), Washington (WA); South Atlantic: District of Columbia (D.C.), Delaware (DE), Florida (FL), Georgia (GA), Maryland (MD), North Carolina (NC), South Carolina (SC), Virginia (VA), West Virginia (WV); West North Central: Iowa (IA), Kansas (KS), Minnesota (MN), Missouri (MO), North Dakota (ND), Nebraska (NE), South Dakota (SD); West South Central: Arkansas (AR), Louisiana (LA), Oklahoma (OK), Texas (TX). Frequency and cost data were calculated in each state and then aggregated into the corresponding region. In addition, A 5-year trend analysis was performed across the different regions for both of the claim counts and the associated cost.

\section{Care provider-level analysis}

All data were aggregated utilizing each unique NPI to calculate the averages per urologist, then the median of these averages was calculated across each region. Gender of the prescribing urologist was also evaluated. Prescribers who wrote fewer than 10 opioid prescriptions to Medicare Part D patients within a given calendar year are omitted from the database to preserve patient confidentiality, and were therefore excluded from our analysis. 


\section{Correlating age-adjusted drug death rate by state with opioid claim count}

Drug-related age-adjusted death rates were obtained from the publicly available CDC WONDER database. ${ }^{20}$ Averaged rates were based on the time frame 2013-2018. ICD-10s (International Classification of Diseases, 10th Revision) for drug poisoning deaths were identified including X40-49, X64, X85, Y11-14.

\section{Statistical analysis}

Descriptive statistics are included as counts and percentages for categorical variables and as means and standard deviations for continuous variables. Pairwise student t-test and Chi-square tests were utilized as appropriate. A p-value $<0.05$ was considered statistically significant. All analyses, graphs and mappings were carried out utilizing R 3.6.3 statistical software.

\section{Results}

Within a 5-year average of opioid claims among urologists, a total of 335,421 beneficiaries (12.3\% of all beneficiaries) made 452,901 opioid claims (3.78\% of all prescription claims by urologists), amounting to a total cost of $\$ 5,357,114$ United States Dollars (USD) ( $0.46 \%$ of all costs for urologist prescriptions).

\section{5-year average regional trends in beneficiaries by state}

From an individual state level, Florida, California and Texas demonstrated the largest number of opioid claims and beneficiaries: 39,062 (3.82\% of total claims), 37,580 (3.19\%), 31,044 (3.63\%) and 30,348, 29,119, 22,917 respectively (Table I). California distributed the greatest total opioid day supply of 246,193. The District of Columbia, Wyoming, and Vermont demonstrated the fewest number of opioid claims: 348 (3.37\% of total claims), 474 (3.68\%), and 535 (2.5\%), respectively, with Alaska having the fewest beneficiaries with 231 (Table I).

States where the highest percentage of opioid claims in relation to all claims included Maine (5.8\%), Utah (5.79\%), and Tennessee (5.51\%). The lowest proportion of opioid claims were identified in New York (2.03\%), Connecticut (2.19\%), and Vermont (2.50\%) (Table I; Figure II).

The highest opioid drug costs were found in California $(\$ 457,757)$, Florida $(\$ 388,632)$, and Georgia $(\$ 274,266)$ compared to Alaska $(\$ 3,355)$, Wyoming $(\$ 4323)$, and DC $(\$ 5000)$, which had the lowest. (Figure II).

The greatest percentage of average proportional annual opioid costs were in West Virginia (1.7\%), followed by South Carolina $(0.99 \%)$ and Kentucky $(0.83 \%)$ whereas the lowest were in Illinois, Vermont and New York $(0.28 \%, 0.25 \%$ and $0.22 \%$ respectively) (Figure II).

\section{Annual trends per urologist}

A total of 9,640 urologic providers were identified within the Medicare Part D database between 2013 and 2017. The mean opioid claim count per provider (5-year average) was 53 (SD: 52) with 
the greatest average for claims in the East South-Central region (AL, KY, MS, TN): 82 (SD; 80), amongst 626 providers. The fewest average claim counts were similar within the Mid Atlantic (NJ, NY, PA) and New England (CT, MA, ME, NH, RI, VT) regions at 37 and 38 (SD: 43 and SD: 31), among 1428 and 505 providers respectively (Table II).

West Virginia had the greatest average total opioid claim count per provider, 90, followed by South Carolina and Arkansas (89, 88 respectively). The states with the fewest average total opioid claims included the District of Columbia, Alaska and New Hampshire (20, 23, 29 respectively) (Table II).

When evaluating the proportion of opioid to total Medicare claims, providers in Michigan, Wisconsin and Missouri had the highest average proportion at $10.63 \%, 9.58 \%$ and 9.15\% respectively. Providers in Connecticut, Wyoming and Vermont made up the three states with the lowest proportion of opioid to total Medicare claims (3.46\%, 3.79\% and 3.86\%) (Table II).

The annual opioid claim count proportion across all nine regions appears relatively unchanged with only a modest decrease noted over the five years queried (Figure IIIA). Despite this, the overall proportion of opioid costs appears to have decreased across all regions year over year (Figure III).

\section{Discussion}

Opioid over prescription and abuse has been well documented across the United States for many decades. With as many as $80 \%$ of post-operative patients in the U.S. receiving an opiate and as few as $27 \%$ of them being utilized, a significant public health, financial and medical gap in demand and utility exists. ${ }^{6-8}$ Within the Medicare Part D prescriber database, we found that $3.78 \%$ of all Urologist Medicare claims involve opioids for a total of 452,901claims and $\$ 5,357,114$. For perspective amongst other surgical specialties within the same Medicare database, opioid prescription claims range from 3.6\% amongst otolaryngologists to as high as $41.45 \%$ amongst neurosurgeons. ${ }^{21-22}$ This large variation across surgical subspecialties may be a result of differences in the acuity of patient populations treated. The variation may also be a function of specialty specific practice patterns or differing levels of engagement and efforts put forward by regional and national professional societies. ${ }^{23-26}$

Significant geographic variability is evident when evaluating claims by provider as well as by state. The states with the highest average proportion of opioid claims to all claims per provider included in Michigan, Wisconsin and Missouri at 10.63\%, 9.58\% and $9.15 \%$ respectively, compared to Connecticut, Wyoming and Vermont as the states with the lowest proportion of claims $(3.46 \%, 3.79 \%$ and $3.86 \%$ respectively) (Table II). This is in contrast to the regions and states with the highest average of opioid claims per provider, which were predominantly within the West North Central and South Atlantic regions. Providers in West Virginia, South Carolina, and Arkansas comprised the top three states with the highest average 
opioid claim per provider at 90, 89, and 88 claims respectively (Table II). Loco regional trends in prescriber habits, familiarity or patient preference may all be contributing to this variation. This pattern of states at highest risk is consistent with previously demonstrated patterns of opioid prescription behavior across multiple specialties. ${ }^{5-7,16-18,21,22,24}$ The exact contribution of Urologists contributing to this pattern is unclear. One speculative theory is that this region overlaps with the portion of the country at a higher risk for nephrolithiasis. Historically demonstrated to have an increased incidence of kidney stones, the colloquial "Stone Belt" portions of the south and eastern United States, in particular North and South Carolina, Georgia, Alabama, Mississippi and Tennessee overlap with this region of increased opioid prescription prevalence. ${ }^{27-29}$ Higher incidences of calculi may predict more frequent encounters and subsequent demand for prescription pain control.

What is less clear is how providers from Michigan, Wisconsin, and Missouri had such high proportions of opioid claims, despite being geographically distant from the states West Virginia, South Carolina, and Arizona (which had the overall highest proportion of opioid claims). When evaluating individual states based on their opioid prescribing laws, we are unable to appreciate any significant legal precedent as they vary drastically state by state. Despite widely accepted medical guidelines and suggested published limits, no general consensus exists in law or practice. ${ }^{19,24}$ As of 2019, over half of the states within the U.S. had some form of legal restriction on the duration and quantity of opioids for opioid naive or post-surgical patients. Most states have 7-day limits with some states even stricter, 5-day (NC, NJ, MN), 3-day (KY) and even 4-day limits exclusive to acute dental or ophthalmic pain (MN). ${ }^{30}$ Further variation is seen when evaluating the quantity of opioids prescribed. For example, Maine restricts the prescribed amount to $100 \mathrm{MME}$ per day compared to Nevada, $90 \mathrm{MME} /$ day or Ohio, $30 \mathrm{MME} /$ day and several other states without amount restrictions at all. All of this variability exists despite CDC advocacy for less than $50 \mathrm{MME}$ per day for 7-day therapy. ${ }^{2,3}$

One consistency across all states (with the exception of Missouri) is the implementation and gradually increasing utilization of Prescription Drug Monitoring Programs (PDMP's) to monitor pharmaceutical prescriptions. Analysis amongst Medicare beneficiaries across 10 U.S. states by Moyo et. al. showed that pre and post PDMP utilization was associated with a decrease in the type, strength and day supply of opioids. ${ }^{33,34}$ Further analysis utilizing the Rhode Island PDMP demonstrated that significant cost savings, especially with regards to Medicare beneficiaries bearing the highest average cost of prescribed opioids, could be achieved through use of generic formulations as well as reduced opioid use. ${ }^{35}$ Our data does demonstrate that in the years preceding 2017, an average decrease of opioid prescriptions year over year across all regions occurred (Figure IIIB). This likely suggests that initiatives, as well as awareness surrounding opioid misuse and over prescription were becoming increasingly widespread. Alternatively, this decrease in prescribing may be related to a nationwide shift towards 
minimally invasive procedures, which has been well documented in the urologic literature. ${ }^{36,37}$ Teasing apart the effects of such trends on indications for opioid use from the effects of regional and national awareness campaigns is an important avenue for future research. It is also possible that the crucial need to reduce opioid prescribing has been an impetus for the quick adoption of minimally invasive procedures with faster recovery times and fewer postoperative pain management considerations.

\section{Study limitations}

The Medicare database unfortunately only includes eligible individuals who are 65 years or older and does not account for patients who classify as self-pay or utilize private insurance. Classification for Urologic providers within the Medicare Part D PUF files is also limited and does not separate by subspecialty, preventing identification of trends within certain subspecialties. Furthermore, we are unable to distinguish which procedures may have been performed and for what conditions, in relation to their pain and prescription duration needs. We cannot adequately evaluate the degree to which chronic versus acute opioid prescriptions may be represented. Unfortunately, based on the structure and content within the Medicare Part D database, many of these limitations may be insurmountable for the scope of this study however do present interesting opportunities for future research through inquiry and cooperation with large insurance providers, health agencies and providers a like.

\section{Conclusions}

Legislation, in addition to awareness of the degree of opioid over prescription appears to be prevalent several years prior to the acknowledgement of the crisis in the US. This suggests providers, including Urologists, have recognized and gradually adjusted practice patterns accordingly to face this challenge. No clear correlation between region or state and prescription claims exists. This is likely because many different factors contribute to the variability in claims including but not limited to each patient's individual health status, prescriber habits, insurance coverage, loco regional policies and even manufacturer marketing. It is more prudent than ever that Urologists implement responsible and reasonable treatment options for every patient, whether with opiates or alternative analgesics, when managing their acute or chronic Urologic pain. 


\section{References}

1. HHS Acting secretary declares public health emergency to address national opioid crisis, U.S. Department of Health and Human Services, 26 Oct. 2017, www.hhs.gov/about/news/2017/10/26/hhs-acting-secretary-declares-public-healthemergency-address-national-opioid-crisis.html.

2. "State prescription drug laws." Centers for Disease Control and Prevention, Centers for Disease Control and Prevention, 27 June 2019, www.cdc.gov/drugoverdose/policy/laws.html.

3. Dowell, D., Haegerich, T., Chou, R.. "CDC Guideline for prescribing opioids for chronic pain - United States, 2016." MMWR. Recommendations and Reports, vol. 65, no. 1, 2016, pp. 1-49., doi:10.15585/mmwr.rr6501e1.

4. Centers for Disease Control and Prevention. Annual surveillance report of drug-related risks and outcomes - United States, 2017. Surveillance Special Report. Published August 31, 2017. Accessed [date] from https://www.cdc.gov/ drugoverdose/pdf/pubs/2017- cdc-drug-surveillance-report.pdf

5. Hill, MV., McMahon, ML., Stucke, RS.. "Wide variation and excessive dosage of opioid prescriptions for common general surgical procedures." Annals of Surgery, vol. 265, no. 4, 2017, pp. 709-714., doi:10.1097/sla.0000000000001993.

6. Theisen, KM., Myrga, JM., Hale, N., et al. "Excessive opioid prescribing after major urologic procedures." Urology, vol. 123, 2019, pp. 101-107., doi:10.1016/j.urology.2018.06.057.

7. Ziegelmann MJ, Joseph JP, Glasgow AE, et al. Wide variation in opioid prescribing after urological surgery in tertiary care centers. Mayo Clin Proc. 2019;94(2):262-274. doi:10.1016/j.mayocp.2018.08.035

8. Fujii MH, Hodges AC, Russell RL, et al. Post-discharge opioid prescribing and use after common surgical procedure. J Am Coll Surg. 2018;226(6):1004-1012. doi:10.1016/j.jamcollsurg.2018.01.058

9. Koo, K., Faisal, F., Gupta, N., et al. "Recommendations for opioid prescribing after endourological and minimally invasive urological surgery: An expert panel consensus." Journal of Urology, vol. 203, no. 1, 2020, pp. 151-158., doi:10.1097/ju.0000000000000514.

10. Hawken, SR., Herrel, LA., Ellimoottil, C., et al. "Trends in inpatient urological surgery practice patterns.” Urology Practice, vol. 3, no. 6, 2016, pp. 499-504., doi:10.1016/j.urpr.2015.10.009.

11. Patel, HD., Srivastava, A., Patel, ND., et al. "A prospective cohort study of post discharge opioid practices after radical prostatectomy: The ORIOLES initiative." European Urology, vol. 75, no. 2, 2019, pp. 215-218., doi:10.1016/j.eururo.2018.10.013.

12. Barham, DW., McMann, LP., Musser, JE., et al. "Routine prescription of opioids for post-vasectomy pain control associated with persistent use." Journal of Urology, vol. 202, no. 4, 2019, pp. 806-810., doi:10.1097/ju.0000000000000304. 
13. Tong, CM., Lucas, J., Shah, A., et al. "Novel multi-modal analgesia protocol significantly decreases opioid requirements in inflatable penile prosthesis patients." The Journal of Sexual Medicine, vol. 15, no. 8, 2018, pp. 1187-1194., doi:10.1016/j.jsxm.2018.05.017.

14. Charlson, ES, Feng, PW, Bui, A, et al. Opioid Prescribing Patterns Among American Society of Ophthalmic Plastic and Reconstructive Surgery Members in the Medicare Part D Database. Ophthalmic plastic and reconstructive surgery, 35(4), 2019, pp. 360-364. https://doi.org/10.1097/IOP.0000000000001266

15. Lopez, CD., Boddapati, BS., Venkat, MD., et al. State Medical Cannabis Laws Associated With Reduction in Opioid Prescriptions by Orthopaedic Surgeons in Medicare Part D Cohort, Journal of the American Academy of Orthopaedic Surgeons: May 11, 2020 - Volume Publish Ahead of Print - Issue - doi: 10.5435/JAAOS-D-19-00767

16. Samuel, D., Nevadunsky, NS., Miller, DT., et al. Opioid prescription by gynecologic oncologists: An analysis of Medicare Part D claims. Current problems in cancer, 100655, 2020. Advance online publication. https://doi.org/10.1016/j.currproblcancer.2020.100655

17. Svider, PF., Arianpour, K., Guo, E., et al. Opioid prescribing patterns among otolaryngologists: Crucial insights among the medicare population. The Laryngoscope, 128(7), 2018, pp 1576-1581. https://doi.org/10.1002/lary.27101

18. Patel, S., \& Sternberg, P. Association Between Opioid Prescribing Patterns and Abuse in Ophthalmology. JAMA ophthalmology, 135(11), 2017, pp 1216-1220. https://doi.org/10.1001/jamaophthalmol.2017.4055

19. Sethi, R., Miller, AL., Bartholomew, RA., et al. Opioid prescription patterns and use among patients undergoing endoscopic sinus surgery. The Laryngoscope, 129(5), 2019, pp 1046-1052. https://doi.org/10.1002/lary.27672

20. CDC Wonder. (2018). https://wonder.cdc.gov/controller/datarequest/D76;jsessionid=1397490CE4E0D29B5ED D31CD5FC5B156Accessed February 11, 2018.

21. Khalid, SI., Adogwa, O., Lilly, DT., et al. "Opioid prescribing practices of neurosurgeons: Analysis of medicare part D.” World Neurosurgery, vol. 112, 2018, doi:10.1016/j.wneu.2017.12.011.

22. Svider, PF., Arianpour, K., Guo, E., et al. "Opioid prescribing patterns among otolaryngologists: Crucial insights among the medicare population." The Laryngoscope, vol. 128, no. 7, 2018, pp. 1576-1581., doi:10.1002/lary.27101.

23. Stepan, JG., Lovecchio, FC., Premkumar, A., et al. Development of an Institutional Opioid Prescriber Education Program and Opioid-Prescribing Guidelines: Impact on Prescribing Practices. The Journal of bone and joint surgery. American volume, 101(1), 2019, pp 5-13. https://doi.org/10.2106/JBJS.17.01645

24. Kurt A Yaeger, MD, Robert J Rothrock, MD, Brian Harris Kopell, MD, Commentary: Neurosurgery and the Ongoing American Opioid Crisis, Neurosurgery, Volume 82, Issue 4, April 2018, Pages E79-E90, https://doi.org/10.1093/neuros/nyx584

25. Finks, JF., Osborne, NH., Birkmeyer, JD. "Trends in Hospital Volume and Operative Mortality for High-Risk Surgery." New England Journal of Medicine, vol. 364, no. 22, 2011, pp. 2128-2137., doi:10.1056/nejmsa1010705. 
26. Hartford, LB., Van Koughnett, J., Murphy, PB., et al. Standardization of Outpatient Procedure (STOP) Narcotics: A Prospective Non-Inferiority Study to Reduce Opioid Use in Outpatient General Surgical Procedures. Journal of the American College of Surgeons, 228(1), 2019, pp. 81-88.e1. https://doi.org/10.1016/j.jamcollsurg.2018.09.008

27. McDonald DC., Carlson K., Izrael D.. Geographic variation in opioid prescribing in the U.S. J Pain. 2012;13(10):988-996. doi:10.1016/j.jpain.2012.07.007

28. Soucie, JM., Thun, MJ., Coates, RJ., et al. "Demographic and geographic gariability of Kidney Stones in the United States." Kidney International, vol. 46, no. 3, 1994, pp. 893899., doi:10.1038/ki.1994.347.

29. Brikowski, TH., Lotan, Y., Pearle, MS.. "Climate-related increase in the prevalence of urolithiasis in the United States." Proceedings of the National Academy of Sciences, vol. 105, no. 28, 2008, pp. 9841-9846., doi:10.1073/pnas.0709652105.

30. Liang, Y, Turner, BJ.. "Assessing risk for drug overdose in a national cohort: Role for both daily and total opioid dose?" The Journal of Pain, vol. 16, no. 4, 2015, pp. 318 325., doi:10.1016/j.jpain.2014.11.007.

31. Davis, CS., Lieberman, AJ., Hernandez-Delgado, H., et al. "Laws limiting the prescribing or dispensing of opioids for acute pain in the United States: A national systematic legal review." Drug and Alcohol Dependence, vol. 194, 2019, pp. 166-172., doi:10.1016/j.drugalcdep.2018.09.022.

32. Feinberg, AE., Chesney, TR., Srikandarajah, S., et al. "Opioid use after discharge in postoperative patients.” Annals of Surgery, vol. 267, no. 6, 2018, pp. 1056-1062., doi:10.1097/sla.0000000000002591.

33. Moyo, P., Simoni-Wastila, L., Griffin, BA., et al. "Impact of prescription drug monitoring programs (PDMPs) on opioid utilization among Medicare beneficiaries in 10 US states." Addiction, vol. 112, no. 10, 2017, pp. 1784-1796., doi:10.1111/add.13860.

34. Agarwal, S., Bryan, JD., Hu, HM., et al. "Association of state opioid duration limits with postoperative opioid prescribing." JAMA Network Open, vol. 2, no. 12, 2019, doi:10.1001/jamanetworkopen.2019.18361.

35. Aroke H., Buchanan A., Wen X., et al. "Estimating the direct costs of outpatient opioid prescriptions: a retrospective analysis of data from the Rhode Island prescription drug monitoring program." J Manag Care Spec Pharm. 2018;24(3):214-24. Available at: https://www.jmcp.org/ doi/10.18553/jmcp.2018.24.3.214.

36. Bachman, AG., Parker, AA., Shaw, MD., et al. Minimally Invasive Versus Open Approach for Cystectomy: Trends in the Utilization and Demographic or Clinical Predictors Using the National Cancer Database. Urology, 103, 2017, pp. 99-105. https://doi.org/10.1016/j.urology.2017.02.018

37. Chughtai, B., Scherr, D., Del Pizzo, J., et al. "National Trends and Cost of Minimally Invasive Surgery in Urology." Urology Practice, vol. 2, no. 2, 2015, pp. 49-54., doi:10.1016/j.urpr.2014.09.002. 


\section{Figures and Tables}

Fig. 1. Regions as defined within the Medicare Part D (PUF) database.
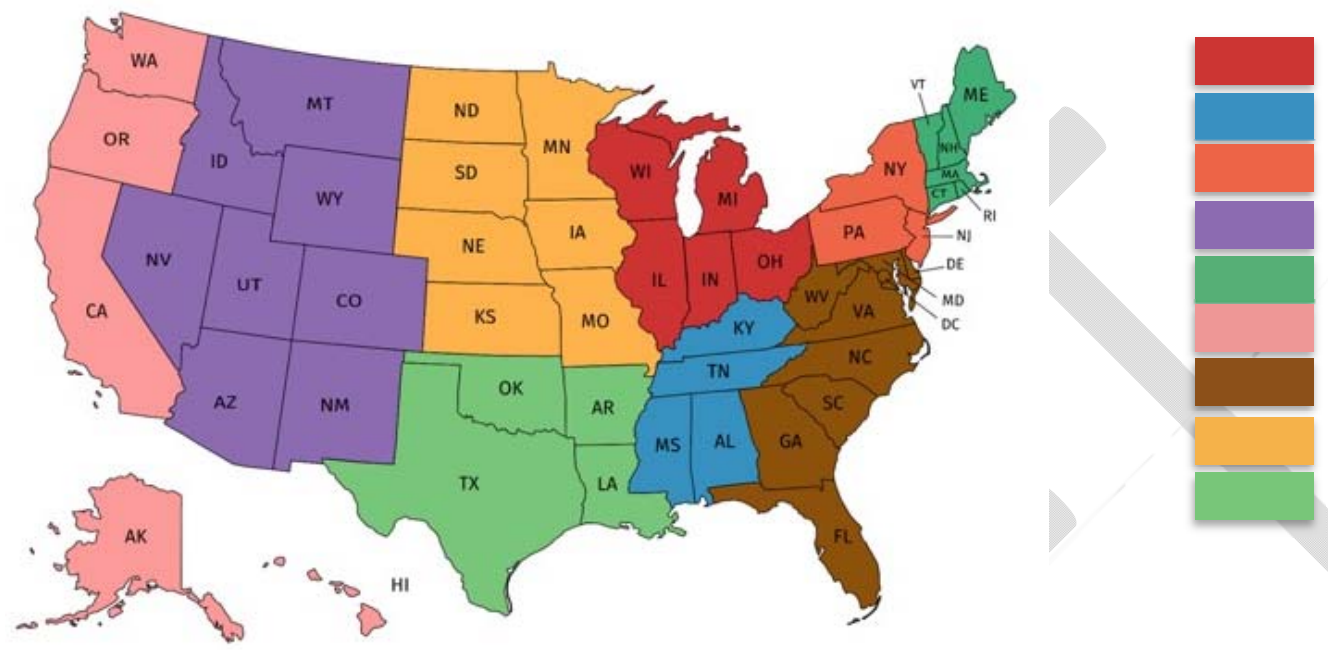

East North Central East South Central Mid-Atlantic Mountain New England Pacific South Atlantic West North Central West South Central

Fig 2. (A) 5-year average annual opioid claim count by sate. (B) Average annual opioid drug cost proportion by state.

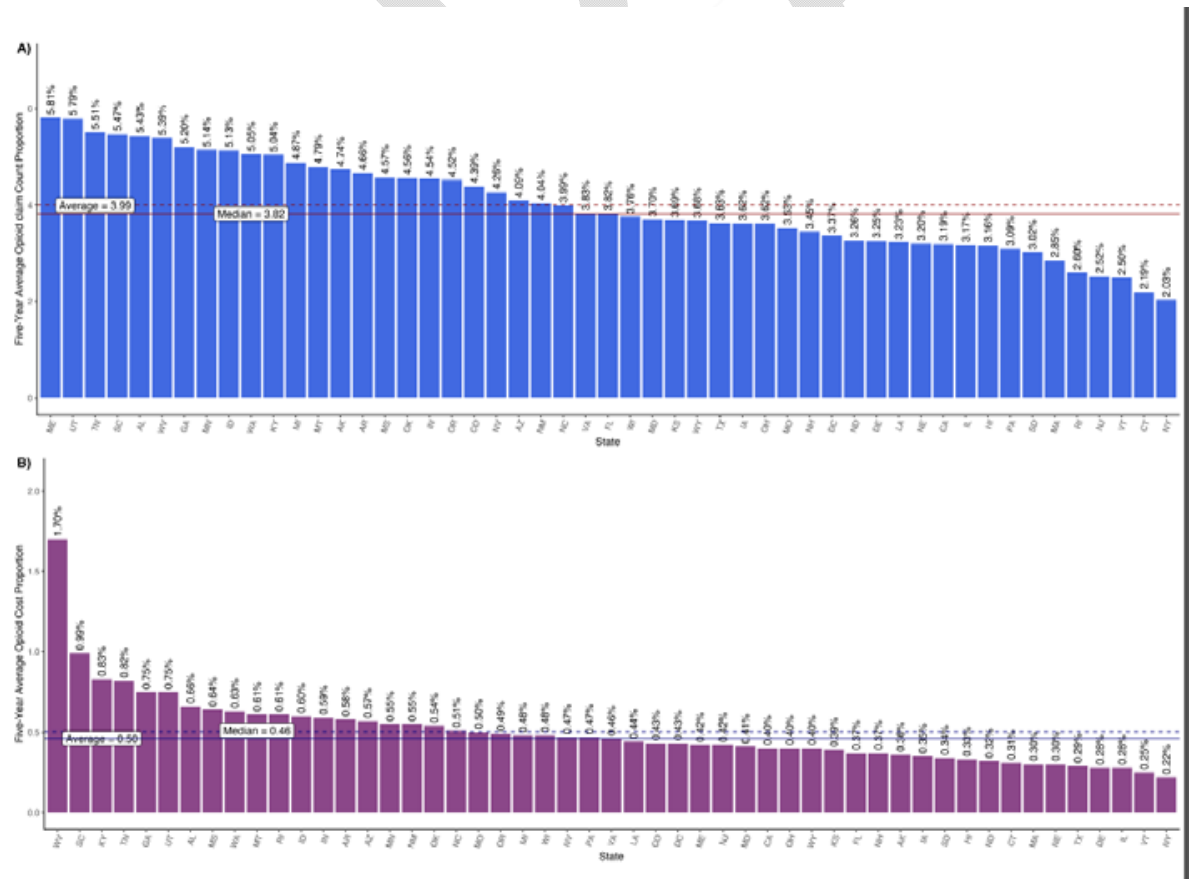


Fig. 3. (A) Annual opioid claim count proportions across the U.S. regions. (B) Annual opioid drug cost proportions across the U.S. regions.

A)

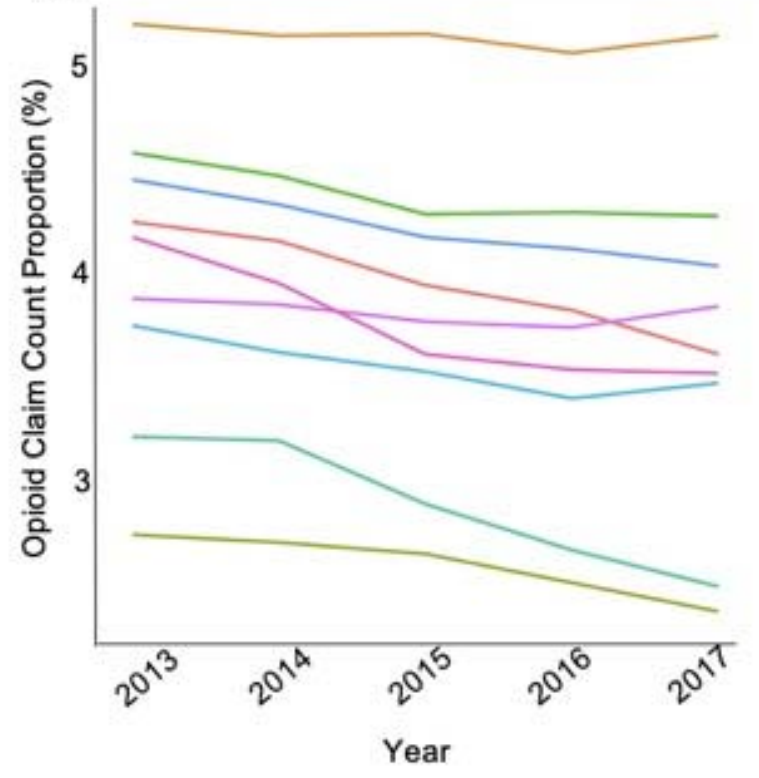

B)

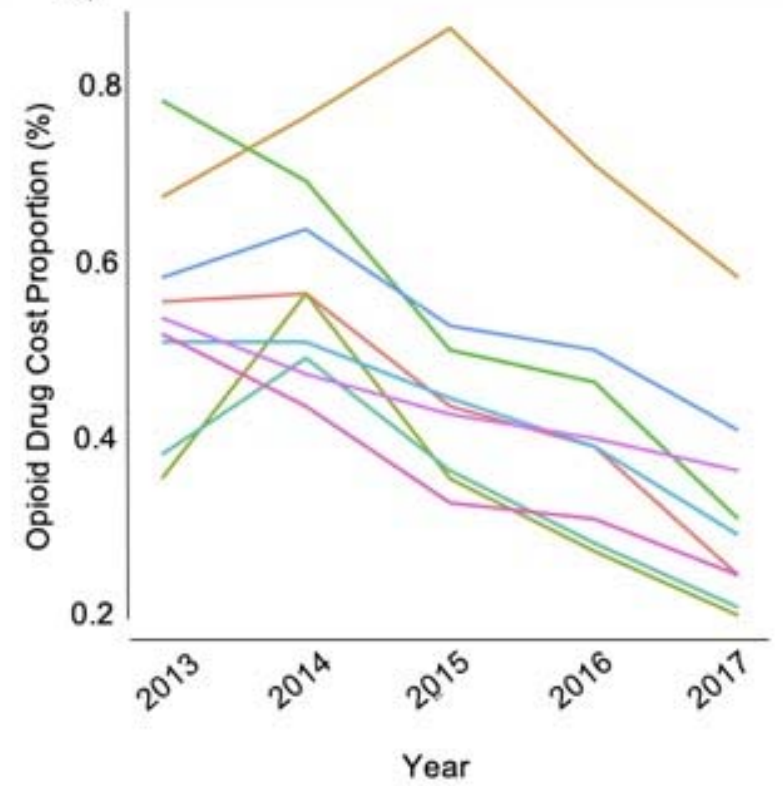

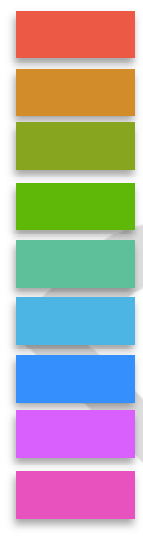

East North Central

East South Central

Mid-Atlantic

Mountain

New England

Pacific

South Atlantic

West North Central

West South Central 
Table 1. 5-year average opioid Medicare Part D claims by urologists, state-level data (2013-2017)

\begin{tabular}{|c|c|c|c|}
\hline Region & State & Opioid claim count & $\begin{array}{c}\text { Opioid claims as a proportion } \\
\text { of total claims }(\%)\end{array}$ \\
\hline \multirow{6}{*}{ East North Central } & IL & 11951 & 3.17 \\
\hline & IN & 13642 & 4.54 \\
\hline & MI & 17333 & 4.87 \\
\hline & $\mathrm{OH}$ & 18884 & 3.62 \\
\hline & WI & 6683 & 3.76 \\
\hline & Total & 68492 & 3.95 \\
\hline \multirow{5}{*}{ East South Central } & $\mathrm{AL}$ & 12945 & 5.43 \\
\hline & $\mathrm{KY}$ & 9211 & 5.04 \\
\hline & $\mathrm{MS}$ & 6388 & 4.57 \\
\hline & $\mathrm{TN}$ & 18237 & 5.51 \\
\hline & Total & 46781 & 5.25 \\
\hline \multirow{4}{*}{ Mid-Atlantic } & $\mathrm{NJ}$ & 10440 & 2.52 \\
\hline & NY & 15008 & 2.03 \\
\hline & PA & 17254 & 3.09 \\
\hline & Total & 42702 & 2.49 \\
\hline \multirow{9}{*}{ Mountain } & $\mathrm{AZ}$ & 9685 & 4.09 \\
\hline & $\mathrm{CO}$ & 5628 & 4.39 \\
\hline & ID & 2623 & 5.13 \\
\hline & MT & 1377 & 4.79 \\
\hline & NM & 1936 & 4.04 \\
\hline & $\mathrm{NV}$ & 3141 & 4.26 \\
\hline & UT & 3139 & 5.79 \\
\hline & WY & 474 & 3.68 \\
\hline & Total & 28004 & 4.42 \\
\hline \multirow{4}{*}{ New England } & $\mathrm{CT}$ & 3709 & 2.19 \\
\hline & MA & 6964 & 2.85 \\
\hline & $\mathrm{ME}$ & 1570 & 5.81 \\
\hline & $\mathrm{NH}$ & 1393 & 3.45 \\
\hline
\end{tabular}




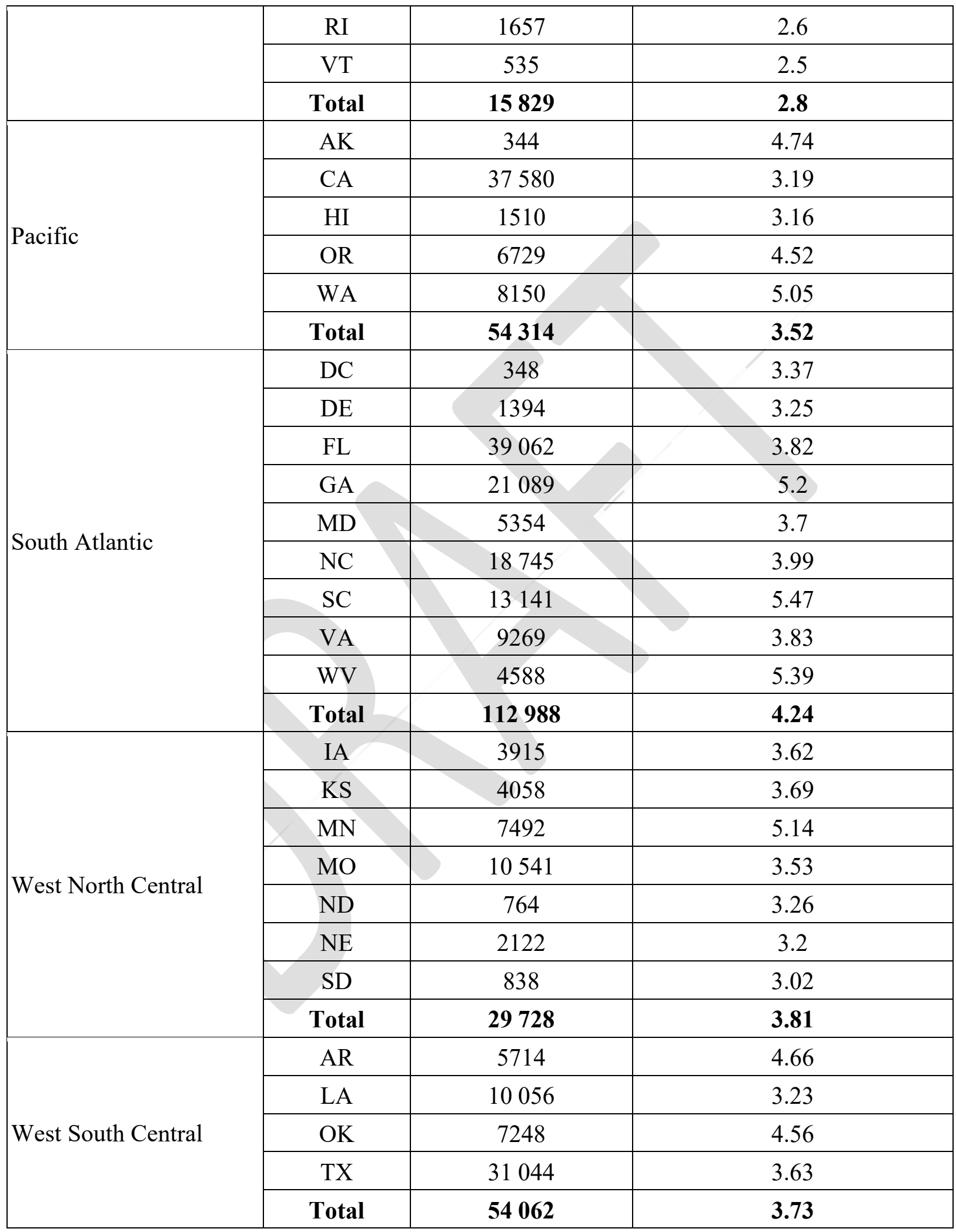


Table 2. 5-year average opioid Medicare Part D claims per urologist, provider-level data (2013-2017)

\begin{tabular}{|c|c|c|c|c|c|c|}
\hline Region & State & $\mathbf{n}$ & $\begin{array}{l}\text { Opioid claim } \\
\text { count }\end{array}$ & \begin{tabular}{|c|} 
Opioid claim \\
proportion to total \\
claims $(\%)$
\end{tabular} & $\begin{array}{c}\text { Female } \\
(\%)\end{array}$ & Male (\%) \\
\hline Overall & & 9640 & $53(52)$ & $6.86(9.18)$ & $883(9.2)$ & $8756(90.8)$ \\
\hline \multirow[b]{5}{*}{ East North Central } & $\mathrm{IL}$ & 403 & $38(28)$ & $8.85(12.56)$ & $46(11.4)$ & $357(88.6)$ \\
\hline & $\mathrm{IN}$ & 213 & $75(87)$ & $6.32(6.59)$ & $16(7.5)$ & $197(92.5)$ \\
\hline & $\mathrm{MI}$ & 375 & $55(65)$ & $10.63(12.21)$ & $47(12.5)$ & $328(87.5)$ \\
\hline & $\mathrm{OH}$ & 385 & $57(39)$ & $7.18(9.82)$ & $29(7.5)$ & $356(92.5)$ \\
\hline & WI & 188 & $44(32)$ & $9.58(13.50)$ & $27(14.4)$ & $161(85.6)$ \\
\hline \multirow[b]{4}{*}{ East South Central } & $\mathrm{AL}$ & 165 & $86(54)$ & $7.04(5.46)$ & $14(8.5)$ & $151(91.5)$ \\
\hline & $\mathrm{KY}$ & 135 & $73(74)$ & $8.31(9.13)$ & $17(12.6)$ & $118(87.4)$ \\
\hline & $\mathrm{MS}$ & 84 & $86(56)$ & $5.76(4.15)$ & $5(6.0)$ & $79(94.0)$ \\
\hline & $\mathrm{TN}$ & 242 & $83(102)$ & $8.57(10.19)$ & $25(10.3)$ & $217(89.7)$ \\
\hline \multirow[b]{3}{*}{ Mid-Atlantic } & $\mathrm{NJ}$ & 319 & $38(25)$ & $4.00(7.05)$ & $17(5.3)$ & $302(94.7)$ \\
\hline & NY & 657 & $31(34)$ & $4.83(7.73)$ & $44(6.7)$ & $613(93.3)$ \\
\hline & $\mathrm{PA}$ & 452 & $45(59)$ & $6.84(11.15)$ & $43(9.5)$ & $408(90.3)$ \\
\hline \multirow[b]{8}{*}{ Mountain } & $\mathrm{AZ}$ & 192 & $57(36)$ & $6.96(7.30)$ & $17(8.9)$ & $175(91.1)$ \\
\hline & $\mathrm{CO}$ & 148 & $44(25)$ & $8.62(12.18)$ & $18(12.2)$ & $130(87.8)$ \\
\hline & ID & 47 & $62(32)$ & $5.47(3.00)$ & $5(10.6)$ & $42(89.4)$ \\
\hline & $\mathrm{MT}$ & 33 & $49(21)$ & $7.21(6.35)$ & $3(9.1)$ & $30(90.9)$ \\
\hline & $\mathrm{NM}$ & 45 & $50(38)$ & $5.63(5.32)$ & $8(17.8)$ & $37(82.2)$ \\
\hline & $\mathrm{NV}$ & 53 & $67(48)$ & $5.60(4.63)$ & $5(9.4)$ & $48(90.6)$ \\
\hline & UT & 61 & $59(41)$ & $7.89(6.83)$ & $5(8.2)$ & $56(91.8)$ \\
\hline & WY & 14 & $38(16)$ & $3.86(1.54)$ & $0(0.0)$ & $14(100.0)$ \\
\hline \multirow[b]{6}{*}{ New England } & $\mathrm{CT}$ & 122 & $37(27)$ & $3.46(4.18)$ & $10(8.2)$ & $112(91.8)$ \\
\hline & MA & 222 & $37(27)$ & $7.03(10.38)$ & $25(11.3)$ & $197(88.7)$ \\
\hline & $\mathrm{ME}$ & 38 & $46(32)$ & $5.96(2.94)$ & $2(5.3)$ & $36(94.7)$ \\
\hline & $\mathrm{NH}$ & 55 & $29(15)$ & $5.79(6.28)$ & $10(18.2)$ & $45(81.8)$ \\
\hline & $\mathrm{RI}$ & 46 & $48(58)$ & $6.29(7.74)$ & $6(13.0)$ & $40(87.0)$ \\
\hline & $\mathrm{VT}$ & 22 & $31(25)$ & $3.79(4.21)$ & $3(13.6)$ & $19(86.4)$ \\
\hline Pacific & $\mathrm{AK}$ & 19 & $23(14)$ & $7.04(5.90)$ & $2(10.5)$ & $17(89.5)$ \\
\hline
\end{tabular}




\begin{tabular}{|l|c|c|c|c|c|c|}
\hline \multirow{5}{*}{} & CA & 974 & $45(34)$ & $6.74(10.09)$ & $115(11.8)$ & $859(88.2)$ \\
\cline { 2 - 7 } & HI & 39 & $46(30)$ & $4.14(3.08)$ & $7(17.9)$ & $32(82.1)$ \\
\cline { 2 - 7 } & OR & 126 & $56(31)$ & $6.79(9.43)$ & $20(15.9)$ & $106(84.1)$ \\
\cline { 2 - 7 } & WA & 201 & $46(25)$ & $7.94(7.57)$ & $31(15.4)$ & $170(84.6)$ \\
\hline & DC & 28 & $20(10)$ & $7.06(8.58)$ & $5(17.9)$ & $23(82.1)$ \\
\cline { 2 - 7 } & DE & 28 & $54(37)$ & $3.84(2.40)$ & $3(10.7)$ & $25(89.3)$ \\
\cline { 2 - 7 } & FL & 678 & $63(49)$ & $6.38(7.62)$ & $32(4.7)$ & $646(95.3)$ \\
\cline { 2 - 7 } & GA & 280 & $81(73)$ & $7.48(7.03)$ & $20(7.1)$ & $260(92.9)$ \\
\cline { 2 - 7 } & MD & 191 & $33(44)$ & $7.45(11.86)$ & $19(9.9)$ & $172(90.1)$ \\
\cline { 2 - 7 } & NC & 321 & $64(56)$ & $6.36(7.18)$ & $19(5.9)$ & $302(94.1)$ \\
\cline { 2 - 7 } & SC & 148 & $89(107)$ & $7.02(6.94)$ & $9(6.1)$ & $139(93.9)$ \\
\cline { 2 - 7 } & VA & 215 & $46(33)$ & $5.41(5.77)$ & $12(5.6)$ & $203(94.4)$ \\
\cline { 2 - 7 } & WV & 56 & $90(111)$ & $7.55(7.24)$ & $2(3.6)$ & $54(96.4)$ \\
\hline South Atlantic & IA & 87 & $53(36)$ & $7.14(8.70)$ & $8(9.2)$ & $79(90.8)$ \\
\cline { 2 - 7 } & KS & 88 & $50(29)$ & $5.57(5.98)$ & $4(4.5)$ & $84(95.5)$ \\
\cline { 2 - 7 } & MN & 169 & $48(29)$ & $8.46(7.28)$ & $20(11.8)$ & $149(88.2)$ \\
\cline { 2 - 7 } & MO & 182 & $62(44)$ & $9.15(13.36)$ & $16(8.8)$ & $166(91.2)$ \\
\cline { 2 - 7 } & ND & 19 & $44(26)$ & $4.50(3.77)$ & $1(5.3)$ & $18(94.7)$ \\
\cline { 2 - 7 } & NE & 55 & $41(22)$ & $7.04(10.14)$ & $5(9.1)$ & $50(90.9)$ \\
\cline { 2 - 7 } & SD & 29 & $40(35)$ & $6.20(9.05)$ & $2(6.9)$ & $27(93.1)$ \\
\hline West North Central & AR & 67 & $88(65)$ & $5.12(3.00)$ & $3(4.5)$ & $64(95.5)$ \\
\hline \multirow{5}{*}{ west South Central } & LA & 177 & $61(47)$ & $5.39(8.05)$ & $16(9.0)$ & $161(91.0)$ \\
\hline & OK & 119 & $68(56)$ & $8.75(11.02)$ & $7(5.9)$ & $112(94.1)$ \\
\hline & TX & 628 & $53(44)$ & $6.21(8.31)$ & $58(9.2)$ & $570(90.8)$ \\
\hline & & & $<0.001$ & $<0.001$ & & 0.015 \\
\hline
\end{tabular}

